$\mathrm{DOE} / \mathrm{BC} / 14899-41$

(DE96001249)

RESEARCH ON OIL RECOVERY MECHANISMS IN HEAVY OIL RESERVOIRS

RECEIVED

AUG 161996

○S霡

Final Report

By

Stanford University Petroleum Research Institute

RECEIVED

Stanford, California

\title{
AUG 161996
}

QSTI

August 1996

Performed Under Contract No. DE-FG22-93BC14899

Stanford University Petroleum Research Institute Stanford, California

\section{Bartlesville Project Office U. S. DEPARTMENT OF ENERGY Bartlesville, Oklahoma}

DISTRIBUTION OF THIS DOCUNENT IS UNLMTED

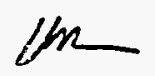




\section{DISCLAIMER}

This report was prepared as an account of work sponsored by an agency of the United States Government. Neither the United States Government nor any agency thereof, nor any of their employees, makes any warranty, expressed or implied, or assumes any legal liability or responsibility for the accuracy, completeness, or usefulness of any information, apparatus, product, or process disclosed, or represents that its use would not infringe privately owned rights. Reference herein to any specific commercial product, process, or service by trade name, trademark, manufacturer, or otherwise does not necessarily constitute or imply its endorsement, recommendation, or favoring by the United States Govemment or any agency thereof. The views and opinions of authors expressed herein do not necessarily state or reflect those of the United States Government.

This report has been reproduced directly from the best available copy.

Available to DOE and DOE contractors from the Office of Scientific and Technical Information, P.O. Box 62, Oak Ridge, TN 37831; prices available from (615) 5768401.

Available to the public from the National Technical Information Service, U.S. Department of Commerce, 5285 Port Royal Rd., Springfield VA 22161 
$\mathrm{DOE} / \mathrm{BC} / 14899-41$

Distribution Category UC-122

\title{
Research on Oil Recovery Mechanisms \\ in Heavy Oil Reservoirs
}

Final Report

\author{
By \\ Stanford University Petroleum Research Institute \\ Stanford, California
}

August 1996

Work Performed Under Contract No. DE-FG22-93BC14899

Prepared for

U.S. Department of Energy

Assistant Secretary for Fossil Energy

Thomas B. Reid, Project Manager

Bartlesville Project Office

P.O. Box 1398

Bartlesville, OK 74005

Prepared by

Stanford University Petroleum Research Institute

Stanford, California 


\section{DISCLAIMER}

Portions of this document may be illegible in electronic image products. Images are produced from the best available original document. 


\section{TABLE OF CONTENTS}

Foreword

Objectives vi

- Description by Projects 1

Project 1: $\quad$ Flow Properties Studies $\quad 1$

1.1 Design and Constructin of an Experiment for Two-Phase Flow in Fractured Porous Media (Ayala, Aziz)

1.2 CT Imaging of Two Phase Flow in Fractured Porous Media (Hughes, Brigham, Castanier)

1.3 An Error Analysis of Relative Permeabilities Calculated Using Conventional Techniques (Qadeer, Aziz, Fayers, Castanier, Brigham)

1.4 Three-Phase Flow Observations in Micromodels (Lolomari, Blunt)

1.5 A Preliminary Study of Relative Permeability in Geothermal Rocks (Satik, Ambusso, Castanier, Horne)

1.6 CT Facility Status and Projects (Castanier) 5

1.6.1 Description of the Facility 5

1.6.2 Software Status

1.6.3 Studies Completed and in Progress 7

Project 2: In-Situ Combustion 9

2.1 A Study of In-situ Combustion on Saudi Tar (Agrawal, Abu-Khamsin) 9

2.2 Modifying In-situ Combustion with Metallic Additives (Castanier, Brigham) 10

2.3 Kinetics of In-situ Combustion 11

Project 3: $\quad$ Steam With Additives $\quad 12$

3.1 Pore Level Visualization of Foam Flow in a Silicon Micromodel (Woody Blunt, Castanier)

3.2 Foams as Mobility Control Agents (Brigham, Castanier) 13

3.3 Characterization of Surfactants in the Presence of Oil for Steam Foam Applications (Abdul-Razzaq, Castanier)

3.4 A Study of Steam Injection in Fractured Media (Sumnu-Dindoruk, Aziz, Brigham, Castanier)

3.4.2 Abstract from SPE 35459 
3.5 Computer Modeling of a Three-Dimensional Steam Injection Experiment (Joshi, Castanier)

3.6 Foam Mechanisms Studies (Castanier, Hanssen) 18

3.6.1 Notes and Acknowledgments

3.6.2 Abstract

3.7 Analytic Steam Injection Model for Layered Systems (Abdul-Razzaq, Brigham, Castanier)

Project 4: Formation Evaluation

4.1 A Finite Difference Model for Free Surface Gravity Drainage (Couri, Ramey) 20

4.2 Drawdown Behavior of Gravity Drainage Wells (Aasen, Ramey) 21

Project 5: Field Support Services . 22

5.1 Steam Flooding a Water Flooded Reservoir -- Performance Evaluation and Prediction (Joshi, Wood, Castanier, Brigham)

5.2 Steam Drive Optimization (Garg)

5.3 Pilot Flooding for Enhanced Recovery (Brigham) 25

5.4 Critique of a Steam Foam Field Pilot (Castanier, Brigham) 26

List of Technical Reports

List of Selected Papers $\quad$. $\quad 28$ 


\section{Foreword:}

The Research on Heavy Oil Recovery Mechanisms at Stanford University has been ongoing for the past twenty years. During this span of time, 106 technical reports have been published by the Department of Energy, over 200 technical papers have been presented at meetings of professional societies, and most importantly, over 120 students have performed research as graduate research assistants and are now employed by the oil industry or research institutions. Funding was provided by the Department of Energy and also by a group of oil companies. The support of industry is very important to us, not only from the financial viewpoint, but also from the constant exchange of ideas with technical experts from the companies. Meetings are held yearly with industry representatives and informal exchange of information is constant. Support from industry has been steady since 1980. SUPRI personel is also active in participating in technical meetings and seminars organized by technical societies and other research organizations. We strongly believe that information exchange is one of the most cost effective way to improve research.

This " final report" describes the work performed since February 1993. During this period, seventeen technical reports have been published. Rather than repeating previous publications, we have decided to include the abstracts of the publications that have been sent to the Department of Energy, or have been published through a technical society. Some ongoing projects will be described in more details. A comprehensive bibliography is included. If the reader is interested in the technical details of any topic presented in this report, he is welcome to request the topical publications on the list or to contact us directly at Stanford University (Petroleum Engineering Department, Green Earth Sciences Building, Stanford, California, 94305). The work performed during the three year period of our grant will be presented following the order of our five main axis of research, namely: Flow properties studies, in-situ combustion, steam injection improvement, formation evaluation and field support services. 


\section{OBJECTIVES}

The goal of the Stanford University Petroleum Research Institute is to conduct research directed toward increasing the recovery of heavy oils. Presently, SUPRI is working in five main directions:

1. FLOW PROPERTIES STUDIES - To assess the influence of different reservoir conditions (temperature and pressure) on the absolute and relative permeability to oil and water and on capillary pressure. To investigate and improve laboratory determination of the flow parameters to be used in reservoir simulation.

2. IN-SITU COMBUSTION - To evaluate the effect of different reservoir parameters on the in-situ combustion process. This project includes the study of the kinetics of the reactions. Effect of metallic additives on the oxydation reactions and determination of the parameters needed to design a field project are also important.

3. STEAM WITH ADDITIVES - To develop and understand the mechanisms of the process using commercially available surfactants for reduction of gravity override and channeling of steam. To study steam injection in fractured media. To study and model foam flow at reservoir conditions to improve gas injection efficiency.

4. FORMATION EVALUATION - To develop and improve techniques of formation evaluation such as tracer tests and pressure transient tests. Knowing the reservoir is the most important step in the design and implementation of any Enhanced Oil Recovery project.

5. FIELD SUPPORT SERVICES - To provide technical support for design and monitoring of DOE sponsored or industry initiated field projects. This includes for example design and analysis of pilot projects, economic evaluation of existing field operations, data gathering and analysis, and theoretical development of models for direct field application. All of this work is done in cooperation with the oil industry, other research organizations and the Department of Energy. 


\section{Description by Projects}

For each of our five main research axis, we will present the salient results of the past three years.

Project 1: FLOW PROPERTIES STUDIES. To assess the influence of different reservoir conditions (temperature and pressure) on the absolute and relative permeability to oil and water and on capillary pressure. and to better estimate reservoir parameters

\subsection{Ayala, R.E.G. and Aziz, K.: Design and Construction of an Experiment for Two- Phase Flow in Fractured Porous Media. A technical report on this topic was published by the Department of Energy. The following is an abstract of this work.}

In numerical reservoir simulation, naturally fractured reservoirs are commonly divided into matrix and fracture systems. The high permeability fractures are usually entirely responsible for flow between blocks and flow to the wells. The flow in these fractures is modeled using Darcy's law and its extension to multiphase flow by means of relative permeabilities. The influence and measurement of fracture relative permeability for two-phase flow in fractured porous media have not been studied extensively, and the few works presented in the literature are contradictory. Experimental and numerical work on two-phase flow in fractured porous media has been initiated. An apparatus for monitoring this type of flow was designed and constructed. It consists of an artificially fractured core inside an epoxy core holder, detailed pressure and effluent monitoring, saturation measurements by means of a CT-scanner, and a computerized data acquisition system. The complete apparatus was assembled and tested at conditions similar to the conditions expected for the two-phase flow experiments. Fine grid simulations of the experimental setup were performed in order to establish experimental conditions and to study the effects of several key variables. These variables include fracture relative permeability and fracture capillary pressure. The numerical computations show that the flow is dominated by capillary imbibition, and that fracture relative permeabilities have only a minor influence. High oil recoveries without water production are achieved due to effective water imbibition from the fracture to the matrix. When imbibition is absent, fracture relative permeabilities affect the flow behavior at early production times. 
1.2 Hughes, R., Brigham, W.E., and Castanier, L.: CT Imaging of Two Phase Flow in Fractured Porous Media was presented at the 21st Annual Workshop on Geothermal Reservoir Engineering, Stanford (January 22-24, 1995). This work also was published as a technical report. The following abstract is below.

The simulation of flow in naturally fractured reservoirs commonly divides the reservoir into two continua - the matrix system and the fracture system. Flow equations are written presuming that the primary flow between grid blocks occurs through the fracture system and that the primary fluid storage is in the matrix system. The dual porosity formulation of the equations assumes that there is no flow between matrix blocks while the dual permeability formulation allows fluid movement between matrix blocks. Since most of the fluid storage is contained in the matrix, recovery is dominated by the transfer of fluid from the matrix to the high conductivity fractures. The physical mechanisms influencing this transfer have been evaluated primarily through numerical studies. Relatively few experimental studies have investigated the transfer mechanisms. Early studies focused on the prediction of reservoir recoveries from the results of scaled experiments on single reservoir blocks. Recent experiments have investigated some of the mechanisms that are dominant in gravity drainage situations and in small block imbibition displacements. The mechanisms active in multiphase flow in fractured media need to be further illuminated, since some of the experimental results appear to be contradictory. This report describes the design, construction, and preliminary results of an experiment that studies imbibition displacement in two fracture blocks. Multiphase (oil/water) displacements will be conducted at the same rate on three core configurations. The configurations are a compact core, a two-block system with a $1 \mathrm{~mm}$ spacer between the blocks, and a two-block system with no spacer. The blocks are sealed in epoxy so that saturation measurements can be made throughout the displacement experiments using a Computed Tomography (CT) scanner.

Preliminary results are presented from a water/air experiment. These results suggest that it is incorrect to assume negligible capillary continuity between matrix blocks as is often done. 
1.3 Qadeer, S., Aziz, K., Fayers, J., Castanier, L.M., and Brigham, W.E.: An error Analysis of Relative Permeabilities Calculated Using Conventional Techniques was presented at the IEA Enhanced Oil Recovery Conference in Bergen Norway, 1994. A technical report on the same topic is in the draft stage. The following is an abstract of this work.

Conventionally, either the Johnson, Bossler and Neumann (JBN) method, or some kind of history matching technique is used to calculate the relative permeabilities from unsteady state displacement experiments. In the JBN method, it is assumed that the capillary forces are negligible, the saturation changes monotonically through the core, and the flow is linear throughout the core. In the numerical technique, only the linear models have been used for history matching. Capillary forces can be accounted for in the numerical model. There has been some work done to show that errors are introduced in the calculated relative permeability curves by using the assumptions in the JBN method. The studies conducted at this time have not shown the severity of errors caused by the nonmonotonic changes in saturation, and the nonlinear flow near the core faces. In this work we have used a 2D radial coordinate numerical simulator. The data from the numerical model and from displacement experiments show that the flow near the core faces is hemispherical. It is also shown, both from in-situ measurements of saturations and from the simulations, that in strongly water wet systems there are strong saturation gradients at the end of drainage displacements even at high rates. This results in nonmonotonic changes in saturation during subsequent imbibition displacements.

The pressure drop and recovery data generated from numerical experiments was used to study the errors introduced in the calculated relative permeability curves by both the JBN and history matching techniques. The results indicate that. because of the initial saturation gradient in the core, the relative permeability curves obtained from imbibition displacements have large errors at low water saturation. As the saturation gradient later diminishes the errors also decrease.

Similar errors were observed during the drainage displacements, but now the errors increase toward the end of the displacement process. For the cases studied, the error is greater during imbibition than in drainage. The errors in both oil and water relative permeabilities in the lower water saturation range can be greater than $100 \%$. 
1.4 Lolomari, T. and Blunt, M.: Three-Phase Flow Observations in Micromodels was published in the 1996 annual report. A draft technical report is in the review process. The following is a summary.

This work is concerned with the description of fluid distribution and pore-scale displacement mechanisms for three phase flow (air, oil and water) and foam using silicon micro models. The micro models are an exact replica of a Berea sandstone and overcome most of the limitations of previous micro models. Previous research on three phase flow using micro models was reviewed. Also, details of a new micro model design and experimental set up are provided. The report on this work will be published in the fall of 1996.

1.5 Satik, C., Ambusso, W., Castanier, L., and Horne, R.: A Preliminary Study of Relative Permeability in Geothermal Rocks was presented at the Geothermal Resources Council Meeting, Reno (October 8-11, 1995), and the 21st Workshop on Geothermal Engineering, Stanford (January 22-24, 1995). A technical report is in the draft stage and will be published through the Geothermal Program. The abstract of this work follows.

This paper reports preliminary experimental and numerical efforts towards obtaining steam-water rela tive permeability and capillary pressure functions under steady-state and adiabatic conditions. In the experimental direction, steady-state nitrogen-water relative permeability experiments were conducted in a Berea sandstone core as a first step. Results obtained from this type of experiment will be compared to those from steam-water relative permeability experiments in order to explore the importance of phase change and heat transfer. Using a high resolution X-ray computer tomography (CT) equipment, saturation distributions along the core were obtained and relative permeabili ties for both nitrogen and water were calculated. Preliminary results showed strong end effects for the core length and total flow rate used in the experiment, which therefore suggested either to use of a longer core or to work at a higher total flow rate. Along with the experiment, numerical simulations of simultaneous in jection of steam and water into a core were also carried out by using a commercial thermal simulator. At steady-state flow conditions, effects of steam quality and total injection rate on saturation profiles were in vestigated. Numerical simulation results suggested a core length of $38.10 \mathrm{~cm}$ for a flat saturation profile re gion to exist under typical experimental conditions. 


\subsection{Castanier, L.M.: CT Facility Status and Projects}

The Petroleum Engineering Department has purchased a new X-ray CT scanner located in the Earth Sciences Green Research Building. SUPRI A is one of the major financial contributors to this project, its operator and one of the main users. The purpose of this summary is to briefly describe the facility, to give some examples of its usage not specifically related to SUPRI A projects and to review the status of the software and hardware.

\subsubsection{Description of the Facility}

The scanner is a modified Pickers 1200SX X-ray machine. The choice of this type of equipment was made because of price, availability, cost of maintenance and unique possibility of vertical positioning modifications. The main features of the hardware are described below.

(a) The scanner: It is a fourth generation scanner where the $\mathrm{X}$-ray tube assembly rotates inside a circle of 1200 detectors. This allows rapid collection of the data (one slice takes 2.3 seconds versus nearly one minute for our older EMI 5005 second generation system). It also improves the spatial definition by a factor of 25 over the older machine allowing measurements of 0.5 by 0.5 by $1 \mathrm{~mm}$ volume elements (voxels). Processing time and quality is also improved by the presence of a Perkin Elmer 3200 computer which processes data on a 512 by 512 matrix format. The X-ray tube is a rotating anode system which give adequate monochromaticity of the $\mathrm{X}$-ray beam while increasing the available intensity thus reducing statistical and beam hardening errors. It also is adequate for multi-energy level scanning, a feature indispensable for proper threephase saturation measurements.

(b) Special modifications: The gantry was modified to allow scans on an axis varying from +20 degrees to -90 degrees from horizontal. The purpose of this modification is to improve measurements of systems where gravity plays an important role; for example, multiphase flow of fluids with large density differences such as gas and liquids. To our knowledge, no other fourth generation scanner, allowing vertical and horizontal scanning, exists in the oil industry. 
The interface between the X-ray generator and the console was modified to allow automatic selection of nonstandard X-ray voltages ranging from $80 \mathrm{keV}$ to $140 \mathrm{keV}$. A computer attached to the system controls automatic scanning of preprogrammed sequences such as rapid dual energy scans of the same slice. This feature should greatly improve the accuracy of three-phase saturation determination.

Better archiving of the data is made possible by addition of an optical disk to replace the conventional medical tape drive. This change increases storage space and speed and allows storage of the raw CT data in addition to the normal picture files. The data can then be retrieved for further processing using the previously developed interpretation software packages.

The positioning table was modified to reproduce the exact position of slices as accurately as possible. A pilot feature allows quick selection of the slices of interest.

\subsubsection{Software Status}

For medical applications, a picture is often adequate. Voxel by voxel processing of the CT data is necessary to obtain quantitative information for parameters such as density, porosity or saturation distributions. Special software needs to be developed and tested for data transfer and display and for quantitative interpretation of the results.

As the data coming out of the CT computers are in a proprietary format not given by the manufacturer of the scanner, we needed to find a program reformatting the data into a usable format for display and processing. After some detective work, a PC based formatting routine was written and tested. This program transforms the raw data obtained from the scanner computer into TIFF files, TEXT files and CT number files.

The TEXT files contain information such as date, slice number and comments on the experiment. The TIFF files are image files that can be immediately displayed and processed on a Macintosh computer, for example. The CT files contain the CT numbers for each voxel of the slice considered. They can be accessed by spreadsheet utilities, such as EXCEL, or can be transferred to the SUN SPARK workstation for further processing. Our existing software, CATSOFT and GENCODE, is being adapted to handle the new CT files formats. It is able to process the data on a voxel by voxel basis to obtain the needed quantitative values of the desired parameters relevant for a given 
process. This software was tested on data obtained by our old EMI 5005 scanner but has not yet been modified for use on the data obtained from the new PICKERS machine. A preliminary test of the software has been initiated.

Phantoms of sandstone containing known amounts of water, gas and oil have been built. They will be used to verify the software accuracy in describing porosity and saturation distribution in a core similar to most of the cores used for flow experiments.

\subsubsection{Studies Completed and in Progress}

In addition to the work presented elsewhere in this report, several projects dealing with various problems of fluid flow in porous media problems have been initiated in collaboration with researchers from other departments and other universities. The CT scanner is proving to be a useful tool in better understanding porous media.

(a) University of California at Santa Cruz Project. Cores were collected from the ocean floor by a team of researchers from the University of California at Santa Cruz. Some of these cores will be used to measure sonic propagation data for seismic survey calibration. The CT scanner was used to examine 48 cores. About half of the cores showed cracks, fractures or major heterogeneities and proved unsuitable for the type of - measurements planned by the UCSC team. The CT scanner helped improve quality control and saved time for those experiments.

(b) University of California at Berkeley Environmental Project. The Mechanical Engineering Department of the University of California at Berkeley has a research project studying the flow of hydrocarbon contaminants in water saturated porous media. We are performing preliminary experiments aimed at the observation of such systems in Berea cores. This project could be the beginning of cooperative efforts between Berkeley and Stanford on a variety of problems dealing with flow through porous media.

(c) Eractured Media Characterization. A long term study of flow through fractured media is continuing in collaboration with the Civil Engineering Department at Stanford University. The first results have been published (Johns et al., 1993). This project is now aimed at better characterization of fractures and insight on flow characteristics of naturally fractured non-sedimentary rocks. 
(d) Miscible Flooding and Geothermal Projects. In our own Petroleum Engineering Department, other research programs are benefiting from the $\mathrm{CT}$ facility.

Observation of miscible or near miscible floods in long cores is in progress and CT determination of adsorbed water in geothermal rocks will be attempted soon. Other projects are planned in enhanced oil recovery research and basic studies of multiphase flow through porous media. 
PROIECT 2: IN-SITU COMBUSTION: To evaluate the effect of different reservoir parameters on the in-situ combustion process. This project includes the study of the kinetics of the reactions.

2.1 Agrawal, V. and Abu-Khamsin, S.: The technical report on A Study of In-situ Combustion on Saudi Tar is completed. The following is the abstract:

Six in-situ combustion tube runs were made using Saudi tar and a matrix of sand and clay. Four of the runs contained iron nitrate while two were control runs without additive. The concentration of iron nitrate was $1 \%, 5 \% 10 \%$ and $20 \%$ by weight of iron nitrate dissolved in the connate water.

The two control runs and the run with $1 \%$ nitrate failed to ignite properly. The front of combustion never propagated along the tube after the first two hours. The runs containing over $10 \%$ iron nitrate burned steadily with the front propagating along the tube. The run with $5 \%$ nitrate burned also but not quite as well. Front temperatures showed little variations and the front velocity did not show any change with iron nitrate concentration. The average fuel concentration was the same in all successful runs. In the failed runs, fuel concentration measured at the location where the front died correspond to about $8 \%$ oil saturation.

The results confirm that iron nitrate is an effective catalyst for the Saudi tar. More work should be done on additive transport and studies of other metals as possible catalysts. 
2.2 Castanier, L.M. and Brigham: Modifying In-situ Combustion with Metallic Additives was accepted for publication in In-situ Journal in 1996. The following is an abstract of this work.

In-situ combustion is the most energy efficient of thermal enhanced oil recovery methods. In light oil reservoirs, too little fuel may be deposited and in very heavy oil reservoirs too much fuel may be deposited. A research program has been ongoing to try to solve these problems. We chose to test water soluble additives to attempt to modify the fuel deposition reactions. In the first stage, kinetics experiments were run on Huntington Beach $\left(18.5^{\circ}\right.$ API) and Hamaca, Venezuela (10.5ZZ $\mathrm{ZZ}^{\circ}$ API) oils in the presence of aqueous solutions of metallic salts. The results were compared with control runs with no metal present. While copper, nickel and cadmium salts had little or no effect; iron, tin, zinc and aluminum increased fuel laydown for Huntington Beach oil. The results were similar for the heavier Hamaca oil. As no reduction in fuel was noticed with any of the metallic additives, ketals were mixed with Hamaca oil in an attempt to reduce fuel. No effect was observed when the ketals were used.

Twenty one combustion tube runs were made in the second stage of the study. They included runs with the oils previously tested in the kinetics apparatus plus two California oils (Cymric light and Cymric heavy) as well as Saudi "tar" $\left(19.7^{\circ} \mathrm{API}\right)$. Iron, tin and zinc salts improved the combustion efficiency in all cases. As a result of the additives, the front velocities were increased. Changes were also observed in the H/C ratios of the fuel, heats of combustion, air requirements and density of the crude produced.

The amount of fuel deposited varied among the oils. For Huntington Beach oil, the amount of fuel increased in the order: zinc, control, tin and iron; while for the Hamaca crude the order was: control, iron and tin. Cymric heavy oil shows the order: control, zinc and iron. Cymric light oil and the Saudi tar.were only tested with iron additive. In the last case the effect of additive concentration was also investigated. We found that for this specific case a minimum near $5 \%$ by weight of hydrated ferrous nitrate in the connate water was needed to improve the combustion.

To date we have not been able to find a suitable additive to reduce fuel deposition. Iron and tin salts seem suitable agents to increase fuel when that is needed. 
2.3 Mamora, D.D., Ramey, H.J., Jr., Brigham, W.E., and Castanier, L.M.: Kinetics of In-situ Combustion. The abstract follows.

Oxidation kinetic experiments with various crude oil types show two reaction peaks at about $250^{\circ} \mathrm{C}\left(482^{\circ} \mathrm{F}\right)$ and $400^{\circ} \mathrm{C}\left(725^{\circ} \mathrm{F}\right)$. These experiments lead to the conclusion that the fuel during high temperature oxidation is an oxygenated hydrocarbon. A new oxidation reaction model has been developed which includes two partially overlapping reactions: namely, low-temperature oxidation followed by high-temperature oxidation. For the fuel oxidation reaction, the new model includes the effects of sand grain size ant the atomic hydrogen-carbon $(\mathrm{H} / \mathrm{C})$ and oxygen-carbon $(\mathrm{O} / \mathrm{C})$ ratios of the fuel. Results based on the new model are in good agreement with the experimental data. Methods have been developed to calculate the atomic $\mathrm{H} / \mathrm{C}$ and $\mathrm{O} / \mathrm{C}$ ratios. These methods consider the oxygen in the oxygenated fuel, and enable a direct comparison of the atomic $\mathrm{H} / \mathrm{C}$ ratios obtained from kinetic and combustion tube experiments. The finding that the fuel in kinetic tube experiments is an oxygenated hydrocarbon indicates that oxidation reactions are different in kinetic and combustion tube experiments. A new experimental technique or method of analysis will be required to obtain kinetic parameters for oxidation reactions encountered in combustion tube experiments and field operations. 
Project 3: STEAM WITH ADDITIVES To develop and understand the mechanisms .... of the process using commercially available surfactants for reduction of gravity override and channeling of steam.

3.1 Woody, F., Blunt, M. and Castanier, L.: Pore Level Visualization of Foam Flow in a Silicon Micromodel was completed. This work was also accepted for publication in In-situ Journal. The abstract is as follows.

This study is concerned with the behavior of foam in porous media at the pore level. Identical, heterogeneous silicon micro models, two dimensionally etched to replicate flow in Berea Sandstone, were used. The models, already saturated with varying concentrations of surfactant and, at times, oil were invaded with air. Visual observations were made of these air displacement events in an effort to determine foam flow characteristics with varying surfactant concentrations, and differing surfactants in the presence of oil. These displacement events were recorded on video tape

The observed air flow characteristics can be broadly classified into two: continuous and discontinuous. Continuous air flow was observed in two phase runs when the micro model contained no aqueous surfactant solution. Air followed a tortuous path to the outlet, splitting and reconnecting around grains, isolating water located in dead-end or circumvented pores, all without breaking and forming bubbles. No foam was created.

Discontinuous air flow occurred in runs containing surfactant -- with smaller bubble sizes appearing with higher surfactant concentrations. Air moved through the medium by way of modified bubble train flow where bubbles travel through pore throats and tend to reside more statically in larger pore bodies until enough force is applied to move them along. The lamellae were stable, and breaking and reforming events by liquid drainage and corner flow were observed in higher surfactant concentrations. However, the classic snap-off process, as described by Roof (1973) was not seen at all.

With oil, we saw coarser bubble texture along with stable water lenses between gas. Events consistent with the drainage of thin spreading oil layers, as well as the collapse of a water film between oil and gas were observed. 
3.2 Brigham, W.E. and Castanier, L.M.: Foams as Mobility Control Agents was presented at the International Energy Agency Symposium Salzburg, Austria, October 17-21, 1993. The abstract follows.

It has long been known that foams flow far less easily through tubing than do either the gases or liquids which make up the foams. From reading the early literature it seems that this knowledge is what triggered the interest in using foamers to reduce the mobility of injected fluids in reservoirs. The actual mechanism in reservoirs, however, is quite different from that in tubing. Instead of many bubbles in a given pore space, there are several pores associated with each bubble. This difference in flow affects the behavior of foaming solutions. For example, adsorption onto the rock surface and absorption into residual oil can greatly affect the rate of propagation of the foamer solution and its effective mobility reduction. The work on foamers at SUPRI is targeted primarily for use as a mobility control agent in steam flooding. However, many of the results found in this work are of general interest to the understanding of foam flow mechanisms. One example concerns the effect of residual oil on foam mobility. Even the method of injection is important here. When no residual oil is in the porous medium, even quite small concentrations of foamer $(0.1 \%)$ can cause considerable blocking action. By contrast at about $12 \%$ saturation, when steam and foamer solution were injected simultaneously, no blocking action was seen, even at high concentrations. When the foamer solution was injected ahead of the steam, significant though smaller reductions in steam mobility were achieved. It has been suggested that noncondensible gas $\left(\mathrm{N}_{2}\right)$ will help improve mobility control when foamers are used in steam flooding. We have experimental evidence in a Cat Scanner which shows that this supposition is true. Surprisingly, a nitrogen foam seems to underride the steam foam to further improve the sweep efficiency. One serious problem about the use of foam is that there is no sound theory which matches foam flow behavior. Recent work on foam flow shows that it requires far more complex mathematics than is usually seen in displacement systems. In brief, simple BuckleyLeverett theory, even modified for variation in mobility and adsorption, does not properly handle the flow behavior. This means that no computer program, now available to predict foam flow are adequate. 
3.3 Abdul-Razzaq and Castanier, L.M: Characterization of Surfactants in the Presence ". - of Oil for Steam Foam Applications. The abstract is below.

The steam foam process has been applied in the oil fields since the late 1970s. The mechanism of the- process, however, is not known fully; particularly the detrimental effects of oil on foam, while known, are still unexplained. This hinders field application as the behavior of surfactants cannot be predicted under field conditions. Understanding the mechanisms of foam generation, stability, and mobility of foam to improve the development of field level projects has been the focus of the attention of many workers of the oil industry. Extensive laboratory studies have been carried out, mostly without oil but some with oil. This study falls in the that category. A one dimensional sandpack (6 $\mathrm{ft} X 2.15$ in. model is used to investigate the behavior of four anionic sulfonate surfactants of varying chemical structure with steam. The study is performed with an crude oil at residual oil saturation of about 12 percent of the pore volume. The observed pressure drops across the various sections of the pack are used to study the behavior of the surfactant. The tested surfactants vary in chain length, aromatic structure and number of ionic charges. A linear toluene sulfonate produced the highest strength foam in presence of the oil at residual saturations, as compared to the alpha olefin sulfonates. This is in contrast to the behavior of the surfactants in the absence of oil, where the alpha olefin sulfonates perform better. The reason for this change in behavior is the relative propagation rate of the foams produced by the surfactants. This conclusion is based on the observation that increase in propagation rate decreases the detrimental effect of oil; while the propagation rate is of little significance without oil. The disulfonate performed better in the presence of oil. The improvement in the performance is embedded in the propagation rate of these surfactants as the rate of propagation in this case is also high. But the true mechanism of improvement in the strength of the foam instead of 'deterioration needs further study. 
3.4 Sumnu-Dindoruk, M.D., Aziz, K., Brigham, W., Castanier, L.: A Study of Steam Injection in Fractured Media. A copy of the abstract from the technical report is included; also is included the abstract of the paper that was presented at the SPE/DOE Tenth Symposium on Improved Oil Recovery, Tulsa (April 21-14, 1996).

\subsubsection{Abstract from theTechnical Report}

Steam injection is the most widely used thermal recovery technique for unfractured reservoirs containing heavy oil. There have been numerous studies on theoretical and experimental aspects of steam injection for such systems.

Fractured reservoirs contain a large fraction of the world supply of oil, and field tests indicate that steam injection is feasible for such reservoirs. Unfortunately there has been little laboratory work done on steam injection in such systems. The experimental system in this work was designed to understand the mechanisms involved in the transfer of fluids and heat between matrix rocks and fractures under steam injection.

Fine grid simulations, where both the fracture and the matrix systems were represented by grids, were used to study the effects of certain flow parameters. Among the fluid flow properties investigated, water-oil capillary pressure of the matrix and gasoil capillary pressure of the fracture were found to have the strongest effect on oil recovery. Matrix gas-oil capillary pressure and fracture water-oil capillary pressure had little effect. Matrix and fracture relative permeabilities also had little effect on recovery.

Experimental design involved the use of both simulations and analytical heat transfer models. Steady state and transient heat transfer models were used to calculate heat losses to determine insulation thickness. Simulations were also used to determine thermocouple locations, maximum expected pressure in the system and injection rates.

Two-phase, continuous steam drive experiments were performed on systems containing water, at differing rates, injection temperatures and back pressures. Saturation distributions, temperature distributions and heat fluxes were measured. The saturations were measured in-situ, both in the fractures and the consolidated rock matrix, by a CT scanner. The results indicated that steam does not enter the matrix, and prefers to flow in the fracture. The matrix is heated by conduction. Cyclic steam injection experiments showed the same results; steam saturation did not develop in the matrix. 
Numerical simulations were used to model both continuous and cyclic steam injection experiments. To model experimental heat losses, heat loss models in the simulator had to be adjusted, based on analytical models. The results from the solution using a variable temperature inner boundary condition, and a convective outer boundary condition, showed good agreement with the experiments and heat transfer coefficients were incorporated into the simulator. After this adjustment, the results from the simulations agreed well with the experiments. Complete matches were made to the heat losses, temperatures and saturations.

The same numerical simulator was used to simulate a case with no external heat losses from the fracture-matrix system. This mimics the process in the field. No steam saturation developed in the matrix. However, when pressure cycling was simulated with no heat losses, matrix steam saturation did develop. This justifies the application of cyclic steam injection in fractured reservoirs, and pinpoints the need to modify any future laboratory work to minimize heat losses from the fractures.

Finally, simulation runs were performed for the laboratory system with oil present. The results were similar to the steam-water experiments. Steam only flowed in the fracture. Oil recovery was found to be mainly due to water imbibition, and conduction was the dominant heat transfer mechanism. When cyclic steam injection was simulated with no external heat losses, steam saturation did develop in the matrix; however, the oil recovery was similar to the case with no cycling, showing that water imbibition was the dominant recovery mechanism.

\subsubsection{Abstract from SPE 35459}

Fractured reservoirs contain a large fraction of the world supply of oil. For viscous crudes, steam is the most successful technique and field tests indicate that steam has the best potential to recover significant amounts of oil from fractured reservoirs. Unfortunately, there has been little laboratory work done on steam injection in such systems.

The experimental system discussed here was designed to understand the mechanisms involved in the transfer of fluids between the matrix rock and the fracture as a result of steam injection. Both continuous and cyclic steam injection experiments were 
performed on a fractured laboratory system. Saturations were measured in-situ both in the fracture and the consolidated matrix by a CT scanner. The results indicated that there was no steam saturation in the matrix, and that conduction was the dominant heat transfer mechanism. Numerical simulations were used to model both continuous and cyclic steam injection experiments. To model heat losses, heat loss models in the simulator had to be adjusted based on the analysis of the heat losses from the laboratory system with analytical models. After this adjustment, the results from the simulations agreed well with the experiments.

When pressure cycling was applied in the simulations with no external heat losses, a considerable amount of steam saturation was observed in the matrix. While the experiments were done with water and steam, simulation runs were also performed for the laboratory system with oil present. Again, steam only flowed in the fracture. Oil recovery was found to be mainly caused by water imbibition into the matrix and heat conduction. Results of this work should be useful in modeling matrix/fracture transfer in dual porosity thermal models.

\subsection{Joshi, S. and Castanier, L.M.: Computer Modeling of a Three-Dimensional Steam Injection Experiment. The abstract of the technical report follows.}

The experimental results and CT scans obtained during a steam-flooding experiment with the SUPRI 3-D steam injection laboratory model are compared with the results obtained from a numerical simulator for the same experiment. Simulation studies were carried out using the STARS (Steam and Additives Reservoir Simulator) compositional simulator. The saturation and temperature distributions obtained and heat flux rates measured in the experimental model at different stages of steam-flooding were compared with those calculated from the numerical simulator. There is a fairly good agreement between the experimental results and the simulator output. However, the experimental scans show a greater degree of gravity override than that obtained with the simulator for the same heat-flux rates. Symmetric sides of the experimental 5-spot show asymmetric heat-loss rates contrary to theory and simulator results. Some utility programs have been written for extracting, processing and outputting the required grid data from the STARS simulator. These are general in nature and can be useful for other STARS users. 
3.6 Castanier, L.M. and Hanssen, J.E.: Foam Mechanisms Studies.

\subsubsection{Notes and Acknowledgments}

This paper was presented at the Reservoir Utilization through Technical Help (RUTH) seminar in Stavangèr, Norway (September 1994). It covers work performed at the Rogaland Research Institute under the RUTH program. Louis Castanier 's sabbatical leave during the Spring and Summer of 1994 was funded by the Fulbright foundation.

Although funding for this study was not provided by the US. Department of Energy or the SUPRI-A Industrial Associates, we feel that the topic is very similar to our own foam flow mechanism project and that this paper will be of interest to tour SUPRI supporters. We are grateful to the RUTH program and the Fulbright Foundation for their support.

\subsubsection{Abstract}

Observations of flow mechanisms for foam systems have been conducted in realistic size micro models (models with pore sizes equal to the size of sandstone pores). As a first step, blocking tests were simulated using an AlphaOlefinSulfonate (AOS) of 16 carbon atoms chain length foamer in concentrations ranging from 0 to $1 \%$ by weight active. The results were compared to previous work in larger size micro models. The foam behavior was strikingly different in the two systems. While in the large pores of previous investigations film generation and breakage appeared to be the dominating mechanisms by which the gas mobility is reduced, in the realistic size system most of the pressure drop across the model appears to be caused by an elastic liquid network made of liquid on solid and liquid in gas films. The events of breakage and formation of lamellae and lenses are rare as compared to the large size systems. Sliding of lamellae over the liquid films covering the grains was often observed as was liquid back flow against the main pressure gradient in the gas phase. Coalescence of two neighboring lamellae frequently occurred and caused formation of thick liquid lenses. The blocking was almost complete, resulting in no flow under gas pressure gradients of up to 20 bars per meter. In order to further investigate the causes of the sliding of the lamellae over the grain covering liquid films, Atomic Force Microscopy was used to investigate the solid liquid interface. Unexpected results were obtained when a surfactant solution was put in contact with a surface of mica. Instead of the mono or bilayers of surfactant molecules expected to be found adsorbed at the surface, a thick layer of surfactant was found. Agregates of a large size (60 nanometers and more in diameter) are present at the top 
surface of this layer when the surfactant solution is above the critical micelle concentration (CMC). More experiments are in progress to better define the amount of surfactant used in this layer. The presence of this previously unknown layer could be an explanation to the elastic behavior of the liquid phase observed in the micro model. It could also partly explain the sliding of some lamellae without breakage frequently seen in the experiments. Further work will include coinjection tests as well as an investigation of the effect of crude oil on the flow mechanisms. The results obtained in the micro models should be compared to similar tests made in sand packs under similar conditions. Oil resistant surfactants will also be tested at that stage.

\subsection{Abdul-Razzaq, Brigham, W.E. and Castanier, L.M.: Analytic Steam Injection Model for Layered Systems. The abstract of the report follows.}

Screening, evaluation and optirnization of the steam flooding process in homogeneous reservoirs can be performed by using simple analytical predictive models. In the absence of any analytical model for layered reservoirs, at present, only numerical simulators can be used. And these are expensive.

In this study, an analytical model has been developed considering two isolated layers of differing permeabilities. The principle of equal flow potential is applied across the two layers. Gajdica's (1990) single layer linear steam drive model is extended for the layered system. The formulation accounts for variation of heat loss area in the higher permeability layer, and the development of a hot liquid zone in the lower permeability layer. These calculations also account for effects of viscosity, density, fractional flow curves and pressure drops in the hot liquid zone. Steam injection rate variations in the layers are represented by time weighted average rates. For steam zone calculations, Yortsos and Gavalas's (1981) upper bound method is used with a correction factor. The results of the model are compared with a numerical simulator. Comparable oil ant water flow rates, and breakthrough times were achieved for $100 \mathrm{cp}$ oil. Results with $10 \mathrm{cp}$ and $1000 \mathrm{cp}$ oils indicate the need to improve the formulation to properly handle differing oil viscosities. 
Project 4: FORMATION EVALUATIONo develop and improve techniques of formation evaluation such as tracer tests and pressure transient tests.

\subsection{Couri, F. and Ramey, H.J., Jr.: A Finite Difference Model for Free Surface Gravity Drainage. The abstract of this work follows.}

The unconfined gravity flow of liquid with a free surface into a well is a classical well test problem which has not been well understood by either hydrologists or petroleum engineers. Paradigms have led many authors to treat an incompressible flow as compressible flow to justify the delayed yield behavior of a time-drawdown test.

A finite-difference model has been developed to simulate the free surface gravity flo $v$ of an unconfined single phase, infinitely large reservoir into a well. The model was verified with experimental results in sandbox models in the literature and ith classical methods applied to observation wells in the Groundwater literature. The simulator response was also compared with analytical Theis (1935) and Arnney et al. (1989) approaches for wellbore pressure at late producing times.

The seepage face in the sandface and the delayed yield behavior were reproduced by the model considering a small liquid compressibility and incompressiblc porou medium.

The potential buildup (recovery) simulated by the model evitenced a different phe nomenon from the drawdown, contrary to statements found in the Groundwatcr literature. Graphs of buildup potential vs. time, buildup seepage face length vs. time. and free surface head and sand bottom head radial profiles evidenced that the liquid refills the desaturating cone as a slow moving surface. The late time pseudo radial behavior was only approached after exaggerated long times. 
4.2 Aasen, J.A. and Ramey, H.J., Jr. wrote Drawdown Behavior of Gravity Drainage Wells. The abstract is as follows.

An analytical solution for drawdown in gravity drainage wells is developed. The free surface flow is viewed as incompressible, and anisotropy effects are included. The well is a line source well, and the reservoir is infinitely large. The model is valid for small drawdowns. The uniform wellbore potential inner boundary condition is modelled using the proper Green's function. The discontinuity at the wellbore is solved by introducing a finite skin radius, and the formulation produces a seepage face. The calculated wellbore flux distribution and wellbore pressures are in fair agreement with results obtained using a numerical gravity drainage simulator. Three distinct flow periods are observed. The wellbore storage period is caused by the moving liquid level, and the duration is short. During the long intermediate flow period, the wellbore pressure is nearly constant. In this period the free surface moves downwards, and the liquid is produced mainly by vertical drainage. At long times the semilog straight line appears. The confined liquid solutions by Theis (1935) and van Everdingen and Hurst (1949) may be used during the pseudoradial flow period if the flowrate is low. New type curves are presented that yield both vertical and horizontal permeabilities. 


\section{Project 5 FIELD SUPPORT SERVICES To provide technical support for design and monitoring of DOE sponsored or industry initiated field projects.}

5.1 Joshi, S., Stanford U., Wood, M.C., Union Pacific Resources Co., Castanier, L.M. and Brigham, W.E.: Steamflooding a Waterflooded Reservoir-- Performance Evaluation and Prediction. The paper SPE 29669 was presented at the Western Regional SPE meeting Long Beach (March 8-10, 1995). The abstract is below.

The Wilmington Steam flood of Union Pacific Resources Co. (UPRC) at Long Beach, CA was initiated in 1989, in a previously water flooded reservoir. Average initial reservoir oil saturation, at the start of the steam flood, was $35 \%$.

Field production data were studied, to derive an overall energy balance for the steam flood, to calculate the steam flood capture efficiency and predict further steam flood performance. Heat-losses due to produced fluids were calculated. Predicted production schedules from the model were history-matched with field production data. All stearn flood calculations were carried out using a PC based spreadsheet program. The major results were as follows:.

The capture efficiency of the Wilmington steam flood was calculated at $60 \%$. This is an acceptable value, taking into account the fact that the reservoir had previously been water flooded to a low oil saturation of $35 \%$.

The calculated heat balance showed a high heat-loss, not only to adjacent formations, but also through produced fluids. Of the cumulative heat injected up to the time of the study, $21 \%$ had been lost to vertical conduction and $21 \%$ through produced fluids.

Predicted production schedules indicated that up to $43 \%$ of the oil in place (at steam flood initiation) would be recovered by the steam flood.

This work was extended in a technical report and presented as a paper at the UNITAR conference. The abstract of the Techno economic study is: The thermal project studied in this work is a tertiary steam flood recovery project started in May 1989 by 
Union Pacific Resources Company (UPRC), in the Tar Zone reservoir of Fault Block II Unit located in the Wilmington Field, Los Angeles County, California.

An analytical steam flood model was applied to determine an overall heat balance for the project and predict future production rates. The model gave a fairly close history match with the production data.

An important feature of the analysis is the determination of heat losses due to produced fluids from the wellbores, a factor sometimes not taken account of in analytical methods. It was calculated that, four years after the steam flood was initiated, almost half (47\%) of the total heat lost from the steam flood was due to produced fluids.

Oil production rates for the steam flood were calculated by using Ramey's generalization of the Marx \& Langenheim method. This was used to match the production history of the project, and thus determine a capture efficiency of $60 \%$ for the steam flood. It was calculated that up to $43 \%$ of the total oil in place (at steam flood initiation) would be recovered by the steam flood.

Since most of the reservoir parameters used in the steam flood analysis cannot be exactly determined, it was decided to treat them as stochastic variables obeying statistical distribution functions. Monte-Carlo simulations were then carried out so that the output oil production at any time could be determined as a probability distribution, rather than a fixed deterministic value. Results obtained indicate that it may be possible to obtain a good estimate of the mean oil recovery and oil recovery distribution by a simple calculation involving the expected values and standard deviations of the input parameters, without going through the complete Monte-Carlo simulation process.

An economic analysis of the steam flood project using capital budgeting, discounted cash flow techniques and Monte-Carlo simulation was also carried out. Some of the input parameters such as oil prices, fuel costs and operating costs were treated as normal random variables. Thus, future oil prices, cashflows, net present value (NPV) and internal rate of return (IRR) for the project were calculated as probability distributions, rather than fixed deterministic values. The project was estimated to have an IRR of $26 \%$ and an NPV of $\$ 2.7$ million at a discount rate of $20 \%$. 
5.2 Garg, A.: Steam Drive Optimization. The abstract is following.

Steam drive is employed in heavy oil reservoirs to improve oil mobility by reducing the viscosity of reservoir fluids, and provides the additional benefit of producing a hydrocarbon rich vapor phase. The light components are condensed at the condensation front and mix with the oil in place to produce a lower viscosity crude oil. Thus steam drive can be an efficient and successful method of heavy oil recovery. Though there have been many steam drive pilots and large-scale operations, an optimization of the steam injection process has not been fully researched.

The objective of this research was to determine an optimal injection schedule to minimize steam use and maximize oil recovery. This objective was achieved by applying economic constraints on steam drive production performance calculations. The primary steps include:

1. Developing a representative steam-drive model to convert heat injection into an oil recovery prediction.

2. Incorporating an economic model to relate injection and handling costs with production revenue.

3. Optimizing the economic function using a multivariable, nonlinear optimization technique.

A general optimization method has been developed to maximize net present value by adjusting injection rate. Prior to steam breakthrough.the maximum injection rate feasible is recommended, then after breakthrough, reductions in injection rate provide the most economically efflcient recovery history. 
5.3 Brigham, W.E.: "Pilot Flooding for Enhanced Recovery." was presented at the International Energy Meeting Bergen, Norway October 1994. The abstract follows:

Pilot flooding, and the prediction and interpretation of pilot flooding results, is far more complex than is full-scale flooding of a reservoir. Certain problems are common to both systems. But, pilot systems are more complex because the flow outside the pat tern is different than it is within the pattern. This variability in outer boundary condi tions does not arise in balanced field wide flood patterns. As a result such items as: gas saturation, inverted versus normal pattern, reservoir pressure, and flow rate outside the pattern, all have a far greater impact on pilot flood recoveries than they do on full-scale floods.

We now have enough waterflooding field data that in most cases we have consid erable confidence in our predictions of waterflood performance. Field experience on EOR projects is far less than it is for water flooding. In addition all EOR projects are far more expensive to operate than is a waterflood. Thus it becomes even more impor tant to interpret pilot floods as intelligently as we know how.

There is a rather bewildering array of conclusions concerning pilot flooding in the SPE literature. It is possible however, to winnow the useful results from these papers and thus present a unified picture of pilot flooding for any recovery process. I will briefly discuss the work done, and the important conclusions reached. Also, I will comment on their conclusions to clarify and sometimes to modify them.

An inverted five-spot pattern is generally useless, but it is acceptable for in-situ combustion, steam and steam with foaming additives. The normal five-spot pattern, or an enclosed pattern of any type, will generally produce reliable recovery results if the pattern is properly balanced. However, under some conditions, a more complex pattern will be necessary. If a pattern is not balanced, the recovery results can be far lower than the optimum. Since the total volume injected in a pilot must be consider ably greater than the volume produced, a well-designed pilot EOR project will not show economic payout. accurate. 


\subsection{Castanier, L.M. and Brigham, W.E.: Critique of a Steam Foam Field Pilot was}

presented' at the International Energy Agency Improved Oil Recovery Meeting Salzburg, Austria (October 17-21, 1993). The following is an abstract of the paper.

From 1981 to 1983, the Stanford University Petroleum Research Institute (SUPRI) performed a field test of steam with foaming additives in the McManus lease of the Kern River field. The test was operated by CORCO on a Petrolewis lease. The goal of this communication is to review the monitoring techniques and injection procedures used during this test in light of the advances in technology that have been made in the past ten years. We hope to draw on a successful but imperfect experiment to provide information that can be used by field operators who wish to run similar pilots. The discussion will start with the choice of a surfactant as foaming agent for a specific field and will point to the importance of laboratory screening. Injection mode (continuous or multiple slugs) and the effect of noncondensable gases will be evaluated. Evaluation of production results and problems excperienced during this evaluation will be described in detail. A new method to accurately measure oil production was developed during the project and we will comment on its applicability. We will show how the logging program that was implemented during the SUPRI test could be improved by better temperature and neutron logging. Tracer tests, pressure transient tests and injecdon profile determinatdon methods all showed some limitations during the pilot. We shall discuss the gap between the informadon available in theory from those methods and what was really achieved in the field. We shall also make suggestions for improvement in designing and interpreting such formation evaluation methods. The goal of a pilot is to provide information on the application of a process to a reservoir. The best monitoring methods should be used to ensure that this objective is met. Examination of past results can be an excellent way to improve current and future projects. 


\section{Technical Reports}

1. Abdul-Razzaq and Castanier, L.M.: "Characterization of Surfactants in the Presence of Oil for Steam Foam Applications," SUPRI TR-88 (June 1993) [DOE/BC/14600-37].

2. Dannert, D.A. and Horne, R.N.: "Ultrasonic Rate Measurements of Multiphase Flow," SUPRI TR-89 (January 1993) [DOE/BC/14600-38].

3. Mamora, D.D., Ramey, H.J., Jr., Brigham, W.E., and Castanier, L,M.: "Kinetics of In-situ Combustion," SUPRI TR-91 (July 1993).

4. Abdul-Razzaq, Brigham, W.E. and Castanier, L.M.: “Analytic Steam Injection Model for Layered Systems," SUPRI TR-93 (June 1993).

5. Joshi, S. and Castanier, L.M.: "Computer Modeling of a Three-Dimensional Steam Injection Experiment," SUPRI TR-94 (August 1993) [DOE/BC/14899-2].

6. Ayala, R.E.G. and Aziz, K.: "Design and Construction of an Experiment for TwoPhase Flow in Fractured Porous Media," SUPRI TR-95 (August 1993) [DOE/BC/14899-3].

7. Couri, F. and Ramey, H.J., Jr.: "A Finite difference Model for Free Surface Gravity Drainage," SUPRI TR-96 (March 1993) [DOE/BC/14899].

8. Aasen, J.A. and Ramey, H.J., Jr.: "Drawdown Behavior of Gravity Drainage Wells," SUPRI TR-97 (September 1993) [DOE/BC/14899].

9. Brigham, W.E. and Castanier, L.M.: "SUPRI Heavy Oil Research Program," Seventeenth Annual Report, SUPRI TR-98 (February 8, 1993 - February 7, 1994) [DOE/BC/14899-16].

10. Brigham, W.E.: "SUPRI Heavy Oil Research Program," Eighteenth Annual Report, SUPRI TR-99 (February 8, 1994 - February 7;, 1995) [DOE/BC/14899-28].

11. Woody, F., Blunt, M., and Castanier, L.M.: "Pore Level Visualization of Foam Flow in a Silicon Micro model," SUPRI TR-100 (January 1996) [DOE/BC/1489932].

12. Dindoruk, M.D.S., Aziz, K., Brigham, W.E., and Castanier, L.M.: "A Study of Steam Injection in Fractured Media," SUPRI TR-101 (December 1995) [DOE/BC/14899].

13. Joshi, Sameer, W.E. Brigham, and L.M. Castanier: "Techno-Economic and Risk Evaluation of a Thermal Recovery Project," SUPRI TR 102 (March 1996)[DOE/BC/14899]. 
14. Brigham, W.E.: "Water Influx, and Its Effect on Oil Recovery," SUPRI TR 103 (May 1996) [DOE/BC/14899].

15. Hughes, Richard G., Brigham, W.E., and Castanier, L.M.: "CT Measurements of Two-Phase Flow in Fractured Porous Media," SUPRI TR 104 (May 1996) [DOE/BC/14899].

16. Agrawal, Vivek K. and Abu-Khamsin, Sidqi: "A Study of In-Situ Combustion on Saudi Tar," SUPRI TR 105 (May 1996) [DOE/BC/14899].

17. Brigham, W.E.: "SUPRI Heavy Oil Research Program," Nineteenth Annual Report, SUPRI TR 106 (February 8, 1995 - February 7, 1996) [DOE/BC/14899].

\section{Selected Technical Papers:}

1993 Castanier, L. M. and W. E. Brigham. Critique of a field pilot of steam with additives. Symposium on Field Applications of Foams, Bakersfield, California; also IEA Symposium, Salzburg.

1993 Brigham, W.E. and L.M. Castanier. Foams as mobility control agents. IEA Symposium, Salzburg.

1994 Sumnu, M.S., K. Aziz, W.E. Brigham and L.M. Castanier. Use of simulators in the design of an experiment for steam injection into a fractured system. SPE 27742, paper presented at the SPE/DOE Ninth Symposium on Improved Oil Recovery, Tulsa.

1994 Castanier, L.M. and J.E. Hanssen: "Foam Mechanisms Studies," Ruth Seminar proceedings, Stavanger (1994).

1994 Mamora, D.D. and W.E. Brigham. The effect of low-temperature oxidation on the fuel and produced oil during in-situ combustion. DOE/NIPER In-situ Conference, Tulsa.

1994 Qadeer, S., K. Aziz, J. Fayers, L.M. Castanier and W.E. Brigham. An error analysis of relative permeabilities calculated using conventional techniques. IEA Enhanced Oil Recovery, Bergen.

1994 Brigham, W.E. Pilot flooding for enhanced recovery, IEA symposium Bergen.

1994 Sumnu, M.D., K. Aziz, W.E. Brigham, and L.M. Castanier. Use of Simulators in the Design of an Experiment for Steam Injection into a Fractured System. SPE/DOE 27742, paper presented at the SPE/DOE Ninth Symposium on Improved Oil Recovery, Tulsa, Oklahoma.

1995 Joshi, Sameer, M.C. Wood, L.M. Castanier and W.E. Brigham. Steamflooding a Waterflooded Reservoir -- Performance Evaluation and Prediction. SPE 29669. 1995 Western Regional Meeting, Bakersfield, California.

1995 Joshi S., Woods M., Castanier L.M. and Brigham W.E. "Steamflooding a Waterflooded Reservoir - Performance Evaluation and Prediction" Sixth UNITAR Conference Houston, Texas, February 12-17 1995 
1995 Satik, Cengiz, W. Ambusso, L.M. Castanier, and R.N. Horne: "A Preliminary Study of Relative Permeability in Geothermal Rocks," Proceedings, Geothermal Resources Council Annual Meeting Stanford (October 8-11, 1995).

1995 Castanier L.M. and Hanssen J.E "Foam Field Tests State of the Art and Critical Review" Eighth European Symposium on Enhanced Oil Recovery Vienna Austria May 15-18 1995.

1996 Sumnu, M.D., W.E. Brigham, K. Aziz, and L.M. Castanier: "An Experimental and Numerical Study on Steam Injection in Fractured Systems," SPE 35459, paper presented at the SPE/DOE Tenth Symposium on Improved Oil Recovery, Tulsa (April 21-24, 1996); also Turkish Petroleum Congress (April 15-17, 1996). 